\title{
Case Report Ewing Sarcoma of the External Ear Canal
}

\author{
Adem Binnetoglu, ${ }^{1}$ Tekin Baglam, ${ }^{1}$ Gulnur Tokuc, ${ }^{2}$ \\ Kiymet Kecelioglu Binnetoglu, ${ }^{3}$ Fatma Gerin, ${ }^{4}$ and Murat Sari ${ }^{1}$ \\ ${ }^{1}$ Department of Otorhinolaryngology-Head and Neck Surgery, Marmara University Pendik Training and Research Hospital, \\ 34899 Istanbul, Turkey \\ ${ }^{2}$ Department of Pediatric Oncology Clinic, Marmara University Pendik Training and Research Hospital, 34899 Istanbul, Turkey \\ ${ }^{3}$ Department of Pediatrics, Marmara University Pendik Training and Research Hospital, 34899 Istanbul, Turkey \\ ${ }^{4}$ Department of Pathology, Marmara University Pendik Training and Research Hospital, 34899 Istanbul, Turkey
}

Correspondence should be addressed to Adem Binnetoglu; adembinnet@hotmail.com

Received 25 February 2016; Revised 12 April 2016; Accepted 13 April 2016

Academic Editor: Rong-San Jiang

Copyright (C) 2016 Adem Binnetoglu et al. This is an open access article distributed under the Creative Commons Attribution License, which permits unrestricted use, distribution, and reproduction in any medium, provided the original work is properly cited.

\begin{abstract}
Background. Ewing sarcoma (ES) is a high-grade malignant tumor that has skeletal and extraskeletal forms and consists of small round cells. In the head and neck region, reported localization of extraskeletal ES includes the larynx, thyroid gland, submandibular gland, nasal fossa, pharynx, skin, and parotid gland, but not the external ear canal. Methods. We present the unique case of a 2-yearold boy with extraskeletal ES arising from the external ear canal, mimicking auricular hematoma. Results. Surgery was performed and a VAC/IE (vincristine, adriamycin, cyclophosphamide alternating with ifosfamide, and etoposide) regimen was used for adjuvant chemotherapy for 12 months. Conclusion. The clinician should consider extraskeletal ES when diagnosing tumors localized in the head and neck region because it may be manifested by a nonspecific clinical picture mimicking common otorhinolaryngologic disorders.
\end{abstract}

\section{Introduction}

Ewing sarcoma (ES) is a malignant tumor that consists of small round cells. It occurs in both skeletal and extraskeletal forms [1-3]. The former mostly occur on long bones of the extremities. Extraskeletal ES (EES), first described by Tefft and colleagues [4], usually originates in the soft tissues of the lower extremities, paravertebral region, chest wall, or retroperitoneum. Rarely, it arises in the head or neck [46]. To our knowledge, there are no previous reports in the English literature of it originating in the external ear canal (EEC).

\section{Case Report}

A 2-year-old boy was admitted via our emergency services with a six-day history of an auricular mass which had not responded to three days of treatment with an amoxicillin clavulanate. There was no history of trauma, fever, or pain or of other features to suggest otitis media, or another upper airway infection. On physical examination, there was a painless, smooth, rubbery mass in the left postauricular area, pushing the conchal cartilage anteriorly and obstructing the EEC (Figure 1(a)). Computed tomography (CT) of the temporal bone showed a $23 \times 12 \mathrm{~mm}$ solid soft tissue mass in the postauricular area that obstructed the EEC (Figure 1(b)). It had regular margins and was homogeneous and hypodense, compatible with an auricular hematoma. After obtaining informed consent, we explored the mass surgically in the expectation that it was likely to be an auricular hematoma. We made an incision behind the ear and elevated a skin flap. We then encountered a solid tumor, which we dissected out from surrounding tissue, obtaining a gross total resection (Figure 1(c)).

The tumor originated from the cartilage part of the EEC, pushing the conchal cartilage anteriorly. Pathological examination revealed a small blue round cell tumor. It was further using a panel of immunohistochemical stains. It stained negatively with markers for melanoma, lymphoma, neuroendocrine carcinomas, and rhabdomyosarcoma, but 


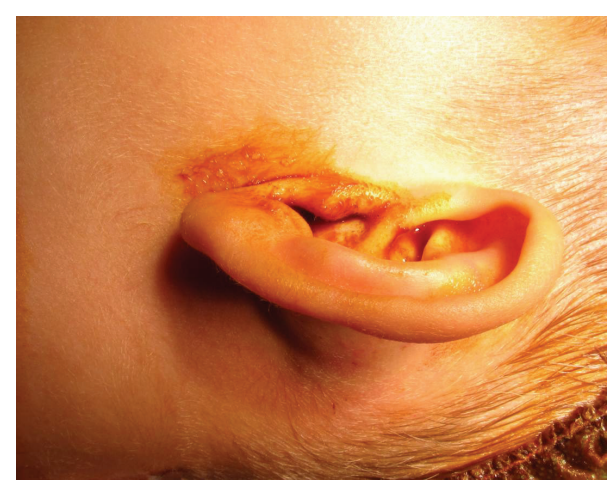

(a)

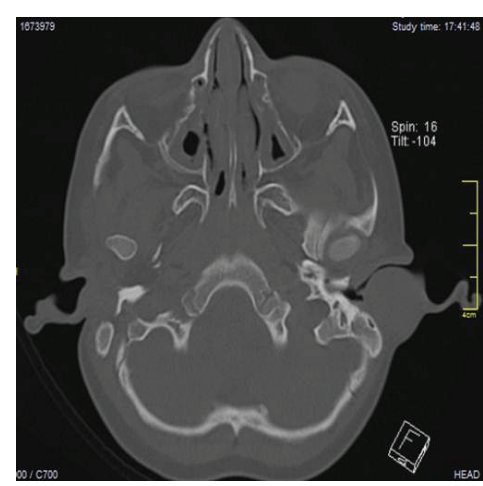

(b)

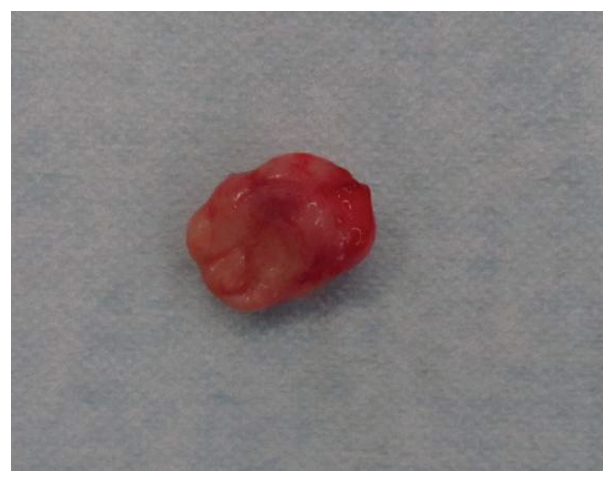

(c)

FIGURE 1: (a) Smooth, rubbery mass in the left postauricular area, displacing the conchal cartilage anteriorly and obstructing the EEC. (b) Axial CT image showing a homogenous, hypodense, solid soft tissue mass in the postauricular area. (c) Fresh, unfixed specimen after surgical removal.

$>50 \%$ of cells stained positively for CD99 and diffusely for FLI1 and vimentin. It had a high proliferative index with Ki-67 (Figure 2). Diagnosis was round cell malignant tumor consistent with ES.

Leukemia markers were negative for CD13, CD33, CD34, CD117, and MPO to rule out acute myeloid leukemia (granulocytic sarcoma).

To exclude a metastatic tumor from an unknown primary site, whole body imaging was performed. A CT scan of the thorax, abdomen, and pelvis was normal. Cranial magnetic resonance imaging (MRI) showed only secondary intensity changes at the operation site. A radionucleotide bone scan was normal (Figure 3). The final diagnosis made was an EES originating in the EEC.

Following surgery, the patient was treated with the VAC/IE chemotherapy regimen for a year. This comprises vincristine $2 \mathrm{mg} / \mathrm{m}^{2}$, adriamycin $75 \mathrm{mg} / \mathrm{m}^{2}$, and cyclophosphamide $1200 \mathrm{mg} / \mathrm{m}^{2}$ given alternately with ifosfamide $1800 \mathrm{mg} / \mathrm{m}^{2} /$ day (5 days) and etoposide $100 \mathrm{mg} / \mathrm{m}^{2} /$ day (5 days) every 21 days. The treatment duration was 12 months. Given that surgery had achieved complete gross and microscopic tumor removal, radiotherapy was not given.

\section{Discussion}

EES is an uncommon tumor, accounting for $1.1 \%$ of soft tissue malignancies [2]. It usually affects males between the ages of 15 and 30 years and has an aggressive course and a high recurrence rate [7]. It may arise from various sites around the body [4-6]. It generally presents as a deep soft tissue mass without the cardinal signs of inflammation, redness, edema, and fever, but sometimes with local pain. Its imaging features are different from those of its skeletal counterpart in that it usually does not directly invade bone. Usually, it will be seen as a soft tissue mass with unclear boundaries and with hemorrhagic and/or cystic changes and areas of necrosis, but without significant calcification $[8,9]$. On CT scans, it is hypodense or of mixed density, usually showing patchy contrast enhancement $[9,10]$. When compared to skeletal muscle, it has low or isointense signal characteristics on T1 weighted MRI and is of high signal intensity on T2 weighted images. Again, it shows patchy contrast enhancement [11-13].

Its clinical and radiological features are nonspecific and a histological diagnosis is essential. In our patient, both the clinical and the radiological picture suggested an auricular hematoma. Following standard histopathological examination, the differential diagnosis included rhabdomyosarcoma, lymphoma, metastatic neuroblastoma, or a desmoplastic tumor. The definite diagnosis required immunohistochemical staining.

EES, when localized, is treated by surgical excision with adjuvant or neoadjuvant chemotherapy. It is responsive to a number of chemotherapeutic drugs, including vincristine, doxorubicin, and cyclophosphamide [14]. The VAC/IE 


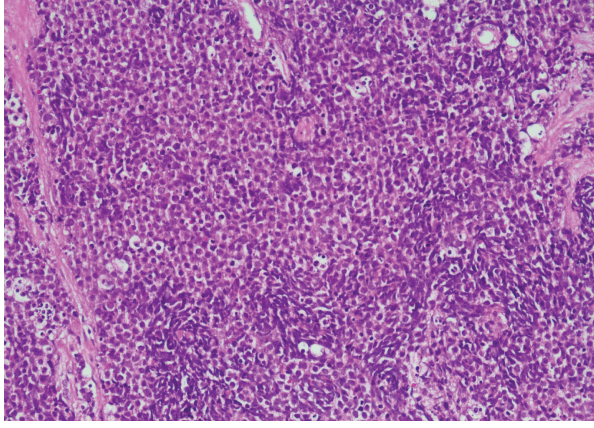

(a)

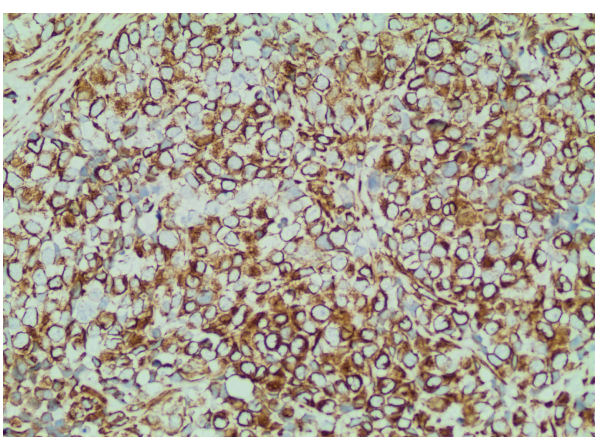

(c)

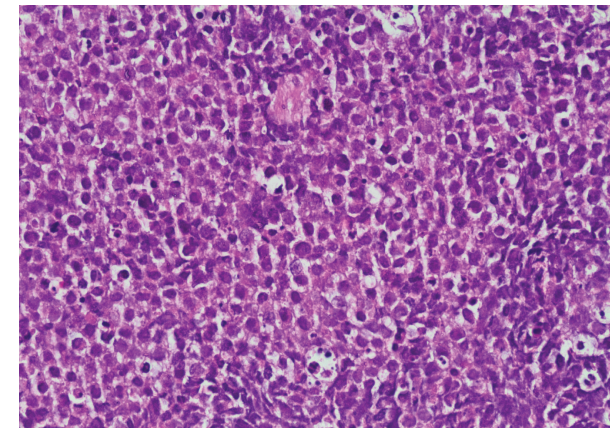

(b)

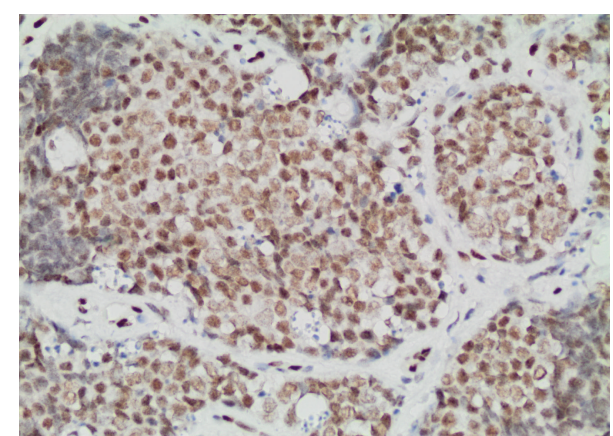

(d)

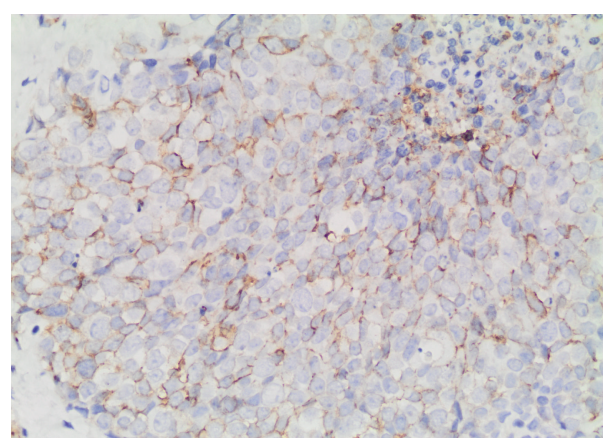

(e)

Figure 2: (a) Tumor cells are uniform small round cells with round nuclei containing fine chromatin, high nuclear to cytoplasmic ratio, and indistinct cytoplasmic membrane (H\&E; 20x). (b) Tumor cells are uniform small round cells with round nuclei containing fine chromatin, high nuclear to cytoplasmic ratio, and indistinct cytoplasmic membrane (H\&E; 40x). (c) Immunohistochemical staining for vimentin (40x). (d) Immunohistochemical staining for FLI1 (40x). (e) Immunohistochemical staining for CD99 (40x).

regimen, as used to treat our patient, is considered standard treatment for EES [15]. Radiotherapy is used to treat localized disease which is considered inoperable, in patients with inadequate surgical margins and in those with a poor response to chemotherapy [16].

The following are reported to be good prognostic indicators: absence of metastases at presentation; tumor size less than $10 \mathrm{~cm}$ diameter; wide excision with clear surgical margins; chemotherapy given for eight or more cycles; a good histological response to induction chemotherapy; and combined modality treatment at presentation [17].

In conclusion, we report a unique case of EES arising from the EEC. A high index of suspicion is needed to diagnose EES, especially when they present in unusual sites such as the head or neck. Their clinical features tend to be nonspecific, and they may mimic common benign conditions, including otorhinolaryngologic disorders.

\section{Competing Interests}

The authors have no potential conflict of interests.

\section{Acknowledgments}

This work was done in Marmara University Pendik Training and Research Hospital. 


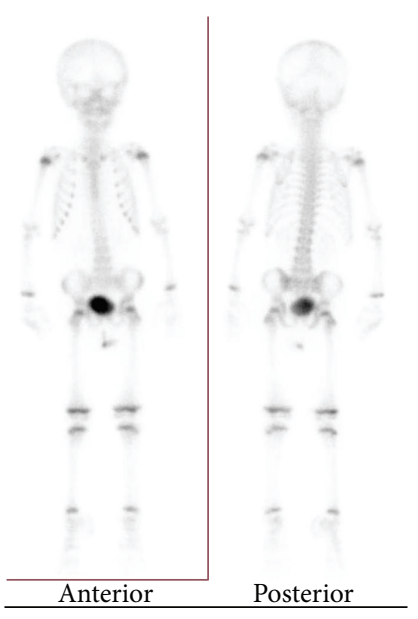

FIGURE 3: Whole body bone scan showing no bone lesions.

\section{References}

[1] A. Iriz, L. Albayrak, and A. Eryilmaz, "Extraskeletal primary Ewing's sarcoma of the nasal cavity," International Journal of Pediatric Otorhinolaryngology Extra, vol. 2, no. 3, pp. 194-197, 2007.

[2] C. H. Smorenburg, C. J. van Groeningen, O. W. M. Meijer, M. Visser, and E. Boven, "Ewing's sarcoma and primitive neuroectodermal tumours in adults: single-centre experience in the Netherlands," Netherlands Journal of Medicine, vol. 65, no. 4, pp. 132-136, 2007.

[3] J. C. Iezzoni and S. E. Mills, “Undifferentiated' small round cell tumors of the sinonasal tract: differential diagnosis update," American Journal of Clinical Pathology, vol. 124, pp. S110-S121, 2005.

[4] M. Tefft, G. F. Vawter, and A. Mitus, "Paravertebral. 'Round cell' tumors in children," Radiology, vol. 92, no. 7, pp. 1501-1509, 1969.

[5] E. A. Klein, A. P. Anzil, P. Mezzacappa, M. Borderon, and V. Ho, "Sinonasal primitive neuroectodermal tumor arising in a longterm survivor of heritable unilateral retinoblastoma," Cancer, vol. 70, no. 2, pp. 423-431, 1992.

[6] S. Gupta, O. P. Gupta, S. Mehrotra, and D. Mehrotra, "Ewing sarcoma of the maxilla: a rare presentation," Quintessence International, vol. 40, no. 2, pp. 135-140, 2009.

[7] T. Z. Zhang and G. W. Xu, Oncology, Tianjin Science and Technology Press, Tianjin, China, 2005.

[8] S.-H. Ng, S.-F. Ko, Y.-C. Cheung, H.-F. Wong, and S.-M. Jung, "Extraskeletal Ewing's sarcoma of the parapharyngeal space," British Journal of Radiology, vol. 77, no. 924, pp. 1046-1049, 2004.

[9] N. P. Rud, H. M. Reiman, D. J. Pritchard, F. J. Frassica, and W. A. Smithson, "Extraosseous Ewing's sarcoma. A study of 42 cases," Cancer, vol. 64, no. 7, pp. 1548-1553, 1989.

[10] O. Delattre, J. Zucman, T. Melot et al., "The Ewing family of tumors-a subgroup of small-round-cell tumors defined by specific chimeric transcripts," The New England Journal of Medicine, vol. 331, no. 5, pp. 294-299, 1994.

[11] T. C. Lim, W. T. L. Tan, and Y. S. Lee, "Congenital extraskeletal Ewing's sarcoma of the face: a case report," Head and Neck, vol. 16, no. 1, pp. 75-78, 1994.
[12] M.-H. Guyot-Drouot, A. Cotten, R. M. Flipo, M. Lecomte Houcke, and B. Delcambre, "Contribution of magnetic resonance imaging to the diagnosis of extraskeletal Ewing's sarcoma," Revue du Rhumatisme, vol. 66, no. 10, pp. 516-519, 1999.

[13] A. Thebert, I. R. Francis, and R. A. Bowerman, "Retroperitoneal extraosseous Ewing's sarcoma with renal involvement: US and MRI findings," Clinical Imaging, vol. 17, no. 2, pp. 149-152, 1993.

[14] S. Ali, K. MacKenzie, R. Reid, G. O’Neill, and I. Ganly, "Cervical extraskeletal Ewing's sarcoma: case report demonstrating radiological features and management," Journal of Laryngology and Otology, vol. 122, no. 9, pp. 998-1001, 2008.

[15] R. Venkitaraman, M. K. George, S. G. Ramanan, and T. G. Sagar, "A single institution experience of combined modality management of extra skeletal Ewings sarcoma," World Journal of Surgical Oncology, vol. 5, article 3, 2007.

[16] A. Pradhan, R. J. Grimer, D. Spooner et al., "Oncological outcomes of patients with Ewing's sarcoma: is there a difference between skeletal and extraskeletal Ewing's sarcoma?" The Journal of Bone \& Joint Surgery-British Volume, vol. 93, no. 4, pp. 531-536, 2011.

[17] A. El Weshi, A. Allam, D. Ajarim et al., "Extraskeletal Ewing's sarcoma family of tumours in adults: analysis of 57 patients from a single institution," Clinical Oncology, vol. 22, no. 5, pp. 374-381, 2010. 


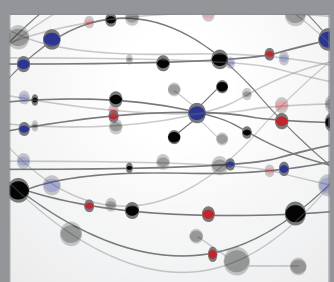

The Scientific World Journal
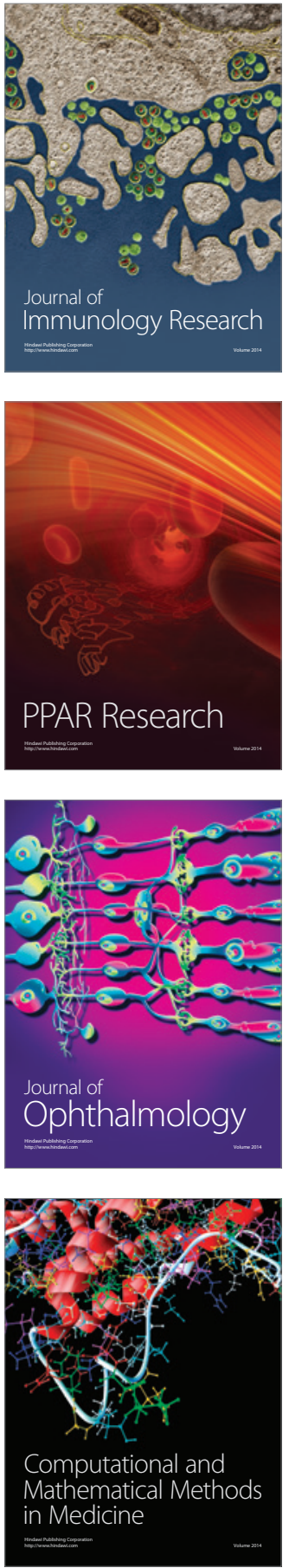

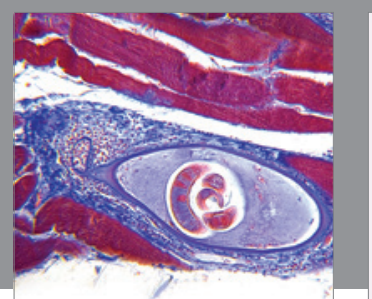

Gastroenterology Research and Practice

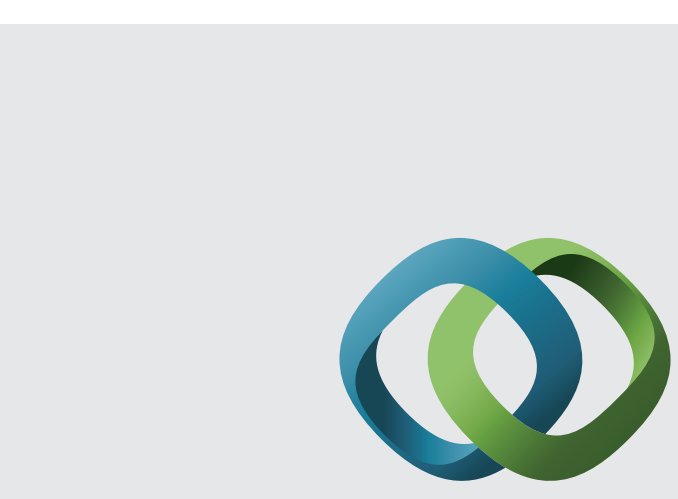

\section{Hindawi}

Submit your manuscripts at

http://www.hindawi.com
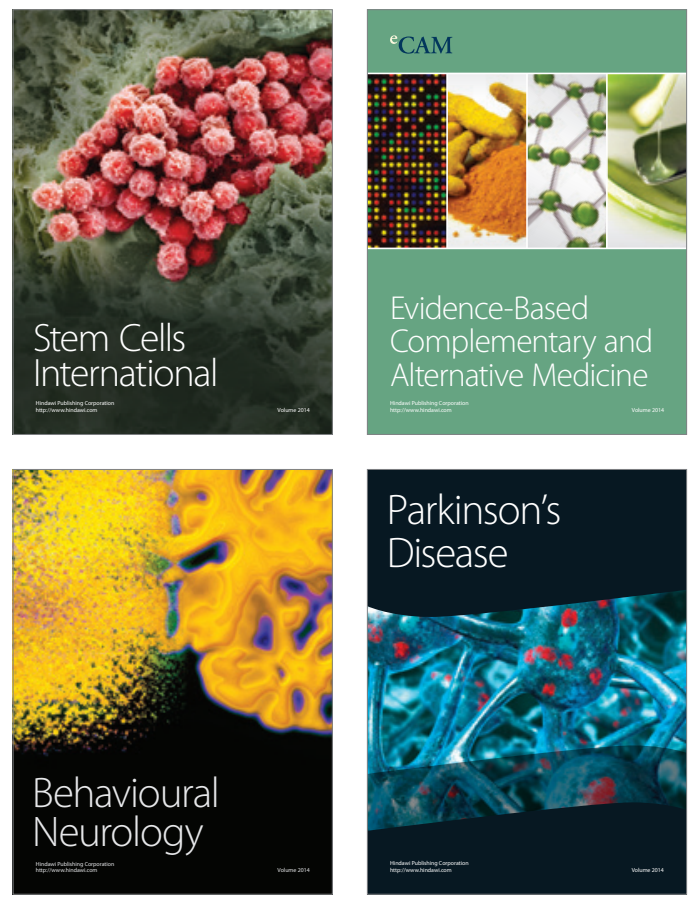
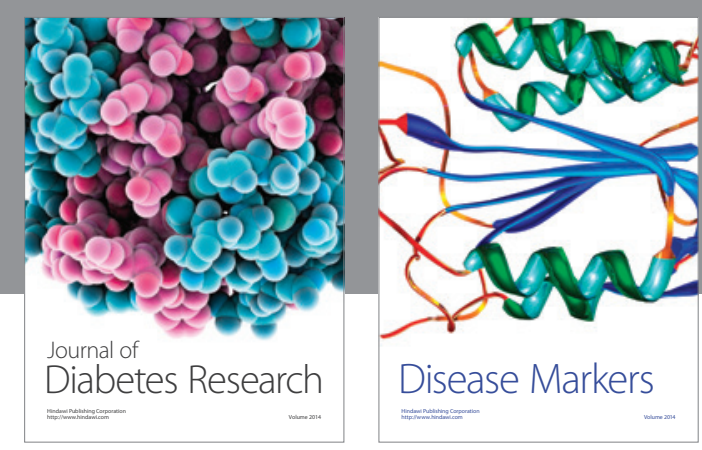

Disease Markers
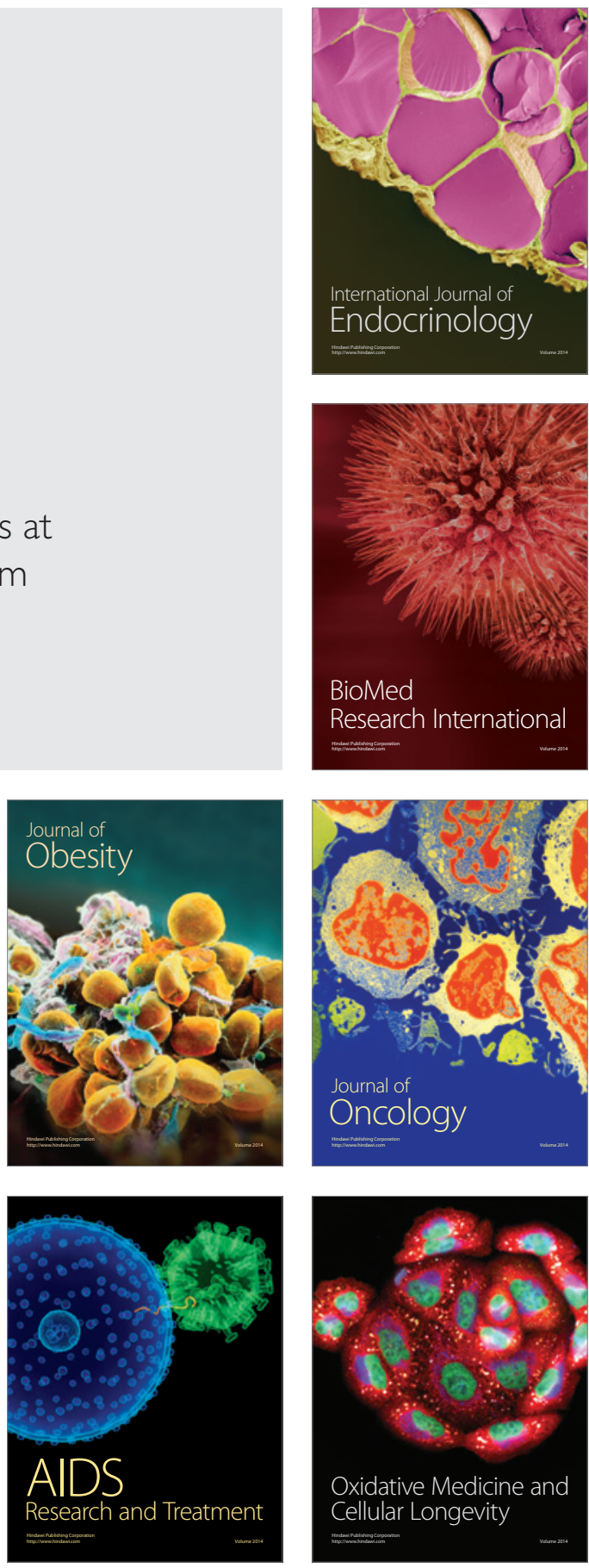